Joanna Siódmiak ${ }^{1 *}$, Tomasz Siódmiak², Agata Tarczykowska², Katarzyna Czirson², Jacek Dulęba², Michał Piotr Marszałł ${ }^{2}$

${ }^{1}$ Department of Laboratory Medicine, Faculty of Pharmacy, Collegium Medicum, Nicolaus Copernicus University, Bydgoszcz, Poland

2Department of Medicinal Chemistry, Faculty of Pharmacy, Collegium Medicum, Nicolaus Copernicus University, Bydgoszcz, Poland

\title{
Metabolic chiral inversion of 2-arylpropionic acid derivatives (profens)
}

\author{
Corresponding author: \\ Joanna Siódmiak \\ Department of Laboratory Medicine, \\ Collegium Medicum, \\ Nicolaus Copernicus University \\ Collegium Medicum \\ No. 9 Sklodowskiej-Curie Street, \\ 85-094 Bydgoszcz, Poland \\ Phone: + 48525854490 \\ Fax: +48525853603 \\ E-mail: asiapollak@wp.p \\ Medical Research Journal 2017; \\ Volume 2, Number 1, 1-5 \\ 10.5603/MRJ.2017.0001 \\ Copyright (C) 2017 Via Medica \\ ISSN 2451-2591
}

\begin{abstract}
2-arylpropionic acid derivatives (profens) are one of the most popular anti-inflammatory, analgesic, and antipyretic drugs. They belong to a group of nonsteroidal anti-inflammatory drugs (NSAID) and exhibit metabolic chiral inversion. Enantiomers of these chiral drugs are often characterised by different pharmacological activity. It is estimated that the values of metabolic chiral inversion of $(R)$-ibuprofen in humans are between 35 and $70 \%$, depending on the condition of the liver and the intake of other medicines, while $(R)$-flurbiprofen undergoes chiral metabolic inversion to its opposed $(S)$ form only in small range. The described phenomenon in the case of $(R)$-ketoprofen is limited to a maximum of around $10 \%$. The metabolic chiral inversion is associated with potentially important pharmacotherapeutic and toxicological consequences, and so an attempt was made to analyse this phenomenon for the most commonly used drugs from the profens group.

Key words: metabolic chiral inversion, ibuprofen, flurbiprofen, ketoprofen, naproxen, chiral drugs, enantiomers
\end{abstract}

Med Res J 2017; 2 (1): 1-5

\section{Introduction}

Currently, according to data of the American Food and Drug Administration (FDA), optically pure compounds represent more than a half of the total investigational new drugs (INDs).

This quantity of tested drugs is reflected in the commercial availability of enantiomers. Eighty percent of the best-selling drugs in the United States are enantiomers of chiral compounds [1].

2-arylpropionic acid derivatives (profens) belong to nonsteroidal anti-inflammatory drugs (NSAID) and have a chiral centre (chiral carbon atom) within the propionic acid moiety, and therefore exist in two enantiomeric forms: $(R)$-enantiomer and $(S)$-enantiomer. Clinically used racemic mixture (racemate) consists of an equimolar mixture of two enantiomers $((R)$ and $(S))$. Profens are widely administered in the inflammatory conditions, to relieve pain and to reduce fever $[2,3]$. Due to presence of the profen forms $(R)$ and $(S)$, a phenomenon called metabolic chiral inversion of these drugs can be observed in the human body. It occurs in the presence of enzymes that determine the change in enantiomeric composition of chiral drug and/or metabolites by inversion of one form to its antipode [4].
The aim of this mini-review is to demonstrate the phenomenon called metabolic chiral inversion of 2-arylpropionic acid derivatives (profens) and to indicate pharmacotherapeutic and toxicological consequences of profens administration in racemic form.

\section{Metabolic chiral inversion of profens}

It has been shown that $(R)$-enantiomers of profens in the presence of coenzyme $A(C o A)$, adenosine triphosphate (ATP) and $\mathrm{Mg}^{2+}$ are transformed to active (S)-forms (Fig. 1). The pathway consists of three parts, beginning from the synthesis of $(R)$-profen thioester with the use of coenzyme A; racemisation of $(R)$-profen thioester and hydrolysis. The first step occurs when formation of thioester from $(R)$-profen and coenzyme $A$ is started. This reaction is catalysed by acyl-CoA synthetase. The next step is racemisation (epimerisation) of the obtained $(R)$-thioester by the activity of epimerase 2-arylpropionic-CoA. Afterwards, newly created thioesters hydrolyse to $(R)$ - and $(S)$-forms, with the use of hydrolase. The metabolic chiral inversion may lead to toxic effects, due to modulation of triglicerydes and phospholipids structures by the acyl-CoA thioester (profenyl-CoA) $[4,5]$. 


\section{(R,S)-ibuprofen}

Ibuprofen (2-[4-(isobutyl)phenyl]propionic acid) is a substance that belongs to nonsteroidal anti-inflammatory drug (NSAID) 2-arylopropionic acid derivatives. Due to the presence of the chiral $\alpha$ atom of carbon in its structure, it is defined as an optically active compound. Ibuprofen exists as a racemic mixture of two enantiomers: $(R)$ and $(S)$, which are characterised by different pharmacokinetic and pharmacodynamic profiles (Fig. 2) [6]. It has been proven in in vitro tests that $(S)$ isomer shows about 160-times higher activity in prostaglandins inhibition compared to $(R)$ enantiomer. (S)-enantiomer equally inhibits the activity of COX-1 and COX2 , while $(R)$-ibuprofen inhibits COX-1 less potently than (S)-form and demonstrates no inhibition of COX-2. It should be emphasised that $(R)$-ibuprofen increases the side effects caused by the intake of racemic mixture, mainly from the gastrointestinal tract [4].

Created thioesters from coenzyme $A$ and ibuprofen can incorporate into triglycerides or phospholipids forming 'hybrids'. In adipose tissue, the estimated elimination half-life $\left(t_{1 / 2}\right)$ of the 'hybrids' is about seven days. The data show that only $(R)$-enantiomer was detected in human adipose tissue, when both $(S)$ - and $(R)$-enantiomers were used in experiment. No accumu-

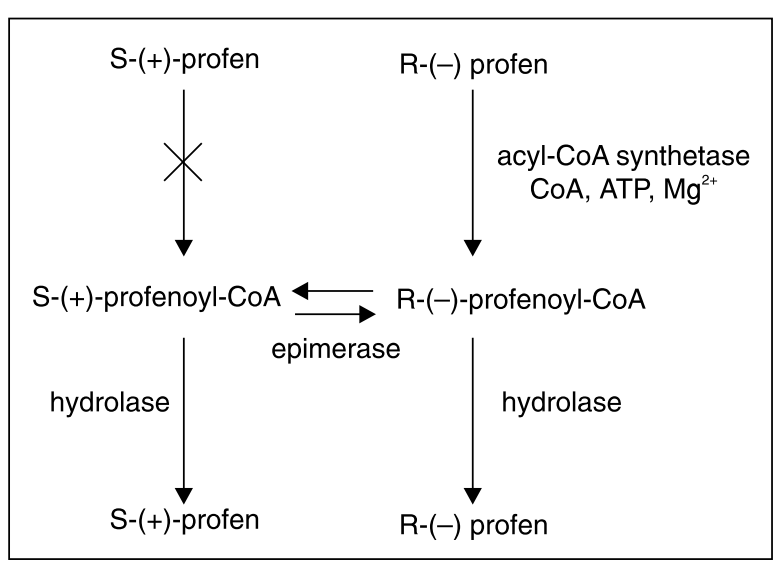

Figure 1. Mechanism of metabolic chiral inversion of profens [4] lation of $(S)$-ibuprofen was noticed. Actually, studies on the effect of 'hybrids' in the adipose tissue and their long $t_{1 / 2}$ have been performed. It has been demonstrated that creation of 'hybrids' with phospholipids may have an influence on the function of the cell membranes. It is estimated that the values of metabolic chiral inversion of $(R)$-ibuprofen in humans are between 35 and $70 \%$, depending on the condition of the liver and the intake of medicines [5, 7].

It was proven that oral administration of pure (S)-ibuprofen allows a stronger analgesic effect in a shorter time, compared with racemic mixture that contained approximately the same amount of active (S)-form. Moreover, the research conducted on 1400 patients showed higher effectiveness of therapy and significantly reduced side effects, while only (S)-ibuprofen was used [8, 9]. Commercially available formulations of this medicine are racemic mixtures (Ibuprofen) or single $(S)$-enantiomer (Dexibuprofen).

\section{$(\boldsymbol{R}, \mathbf{S})$-flurbiprofen}

Another one of the broadly applicable nonsteroidal anti-inflammatory drugs of 2-arylpropionic acid derivatives is $(R, S)$-flurbiprofen [2-(2-fluoro-4-biphenyl)-propionic acid]. This drug possesses a chiral centre and therefore exists in two enantiomeric forms: $(R)$ - and $(S)$-flurbiprofen, which demonstrate various pharmacokinetic and pharmacodynamic activities (Fig. 3). Nevertheless, clinically $(R, S)$-flurbiprofen is used as a racemic mixture, not as an individual enantiomer [10-12]. (S)-enantiomer exhibits an inhibitory effect on cyclooxygenase (COX-2), thus anti-inflammatory action is determined. This enantiomer also shows activity towards cyclooxygenase-1 and thereby induces gastrointestinal side effects. Analysing the influence of $(R)$-form, it has been reported that this enantiomer has no effect on cyclooxygenase (alike COX-1 and COX-2) and is therefore less toxic to the kidneys and gastrointestinal tract, and what is important, in vivo in a small range it undergoes chiral metabolic inversion to its opposed form $(S)[13,14]$. Currently, the mechanism of

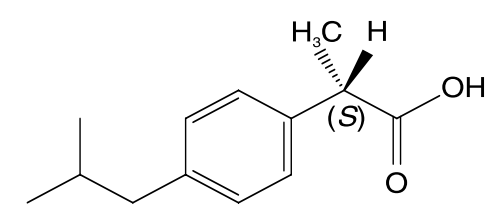

(S)-ibuprofen<smiles>CC(C)Cc1ccc([C@@H](C)C(=O)O)cc1</smiles>

(R)-ibuprofen

Figure 2. Molecular structures of $(S)$ - and $(R)$-ibuprofen 


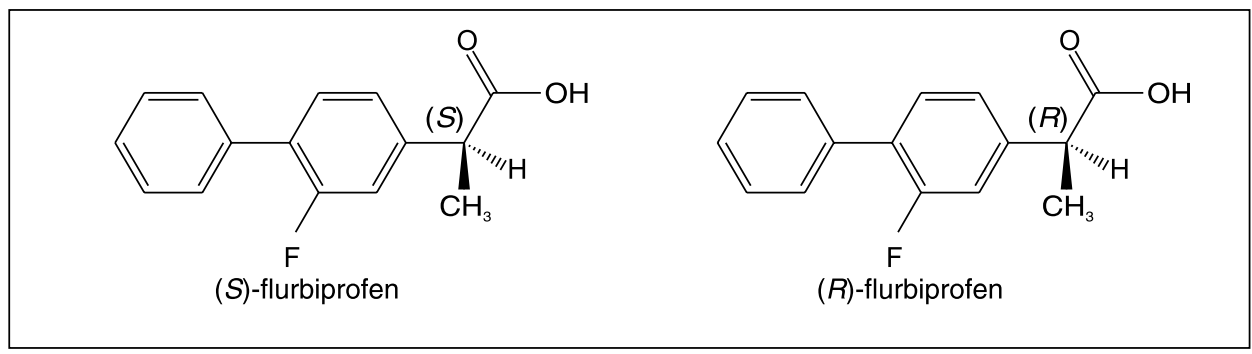

Figure 3. Molecular structures of $(S)$ - and $(R)$-flurbiprofen<smiles>C[C@@H](S)c1cccc(C(=O)c2ccccc2)c1</smiles>

(S)-ketoprofen<smiles>C[C@@H](C(=O)O)c1cccc(C(=O)c2ccccc2)c1</smiles>

(R)-ketoprofen

Figure 4. Molecular structures of $(S)$ - and $(R)$-ketoprofen

molecular action of $(R)$-flurbiprofen is being investigated and it seems to be not related with COX inhibition. It has been proven in cell lines and animal models that $(R)$-enantiomer might be useful in oncology in treatment of colon and prostate cancers [15-19].

\section{(R,S)-ketoprofen}

The next representative of 2-arylpropionic acids derivatives is ketoprofen (2-(3-benzoylphenyl)-propionic acid) [20, 21]. The pharmacological actions of ketoprofen are similar to other NSAIDs, so the anti-inflammatory and analgesic effects are observed due to the inhibition of cyclooxygenase-2 (COX-2). The drug also expresses COX-1 inhibiting activity, and this is the reason why it enhances the risk of gastrointestinal side effects while repeatedly taken orally [22]. The particle is also a chiral compound since it possesses a centre of asymmetry. Ketoprofen, analogically as all 2-arylpropionic acid derivatives, exists in two forms: $(S)$ - and (R)-enantiomer (Fig. 4). What is important, only $(S)$-enantiomer of ketoprofen possesses the pharmacological activity, while $(R)$-enantiomer is either completely inactive or possesses low activity $[23,24]$.

It was confirmed that the chiral metabolic inversion of $(R)$ to $(S)$-ketoprofen is limited to around 10\% [25]. Other authors claim that no relevant enantiomeric inversion of $(R)$ - to $(S)$-form has been registered $[4,26,27]$.
Commercially available formulations of this drug are racemic mixtures (ketoprofen) or single $(S)$-enantiomer (dexketoprofen).

\section{(S)-naproxen}

The last described drug from 2-arylpropionic acid derivatives is naproxen (2-[6-methoxy-2-naphthyl]-propionic acid) (Fig. 5). Due to the well documented hepatotoxicity and the effect of increasing the burden on renal clearance of $(R)$-naproxen, it is the only NSAID that is administrated as a stereochemically pure (S)-enantiomer. Similarly to other NSAIDs, naproxen is used as a treatment of arthritis, febrile syndrome, and pain because of its analgesic, antipyretic, and anti-inflammatory activity. Naproxen is a nonselective COX inhibitor with a balanced inhibitory effect on both COX-isozymes (COX-1 and COX-2) [28-30]. This drug possesses also a chiral centre, and it was observed in in vitro tests concerning inhibition of prostaglandin synthesis that the activity resides mostly in the $(S)$-enantiomer. The $(S)$-naproxen is 28-times more active than the corresponding $(R)$-enantiomer [31]. Jackson et al. claim that the $(S)$ form has approximately 150 -times higher activity than the $(R)$ form [32]. Most of the NSAIDs are available at the market as racemates or single enantiomers, as was mentioned before, but naproxen is an exception because it is sold only as an (S)-enantiomer and not as a racemic mixture. 
<smiles>COc1ccc2cc([C@@H](C)C(=O)O)ccc2c1</smiles>

(S)-naproxen<smiles>COc1ccc2cc([C@@H](C)C(=O)O)ccc2c1</smiles>

$(R)$-naproxen

Figure 5. Molecular structures of $(S)$ - and $(R)$-naproxen

\section{Conclusions}

The phenomenon of metabolic chiral inversion occurs in humans and is associated with potentially important pharmacotherapeutic and toxicological consequences. Enantiomers of chiral drugs are often characterised by different pharmacological activity. Therefore, because of these effects and the considerable popularity of these drugs, in clinical practice administration only of $(S)$-enantiomers of profens (including dexibuprofen and dexketoprofen) should be considered. Further studies on metabolic chiral inversion of enantiomers in terms of pharmacovigilance are needed.

\section{References}

1. Wu L, Vogt FG. A review of recent advances in mass spectrometric methods for gas-phase chiral analysis of pharmaceutical and biological compounds. J Pharm Biomed Anal. 2012; 69: 133-147, doi: 10.1016/j. jpba.2012.04.022, indexed in Pubmed: 22579598.

2. Siódmiak T, Ziegler-Borowska M, Marszałł M. Lipase-immobilized magnetic chitosan nanoparticles for kinetic resolution of $(R, S)$-ibuprofen. Journal of Molecular Catalysis B: Enzymatic. 2013; 94: 7-14 doi: 10.1016/i.molcatb.2013.04.008.

3. Siodmiak T, Ruminski JK, Marszall MP. Application of Lipases from Candida rugosa in the Enantioselective Esterification of $(\mathrm{R}, \mathrm{S})$-Ibuprofen. Current Organic Chemistry. 2012; 16(8): 972-977, doi: 10.2174/ /138527212800194728.

4. Wsól V, Skálová L, Szotáková B. Chiral inversion of drugs: coincidence or principle? Curr Drug Metab. 2004; 5(6): 517-533, indexed in Pubmed: 15578945

5. Tegeder I, Williams K, Geisslinger G. Metabolic Chiral Inversion of 2-Arylpropionic Acids. In: Eichelbaum M, Testa B, Somogyi A. ed. Stereochemical Aspects of Drug Action and Disposition. Springer, Berlin-Heidelberg 2003: 341-354

6. Neupert W, Brugger R, Euchenhofer C, et al. Effects of ibuprofen enantiomers and its coenzyme A thioesters on human prostaglandin endoperoxide synthases. Br J Pharmacol. 1997; 122(3): 487-492, doi: 10.1038/sj.bjp.0701415, indexed in Pubmed: 9351505.

7. Rainsford KD. Ibuprofen: A Critical Bibliography Review. Taylor \&Francis, London 1999: London.

8. Bonabello A, Galmozzi MR, Canaparo R, et al. Dexibuprofen (S+-isomer ibuprofen) reduces gastric damage and improves analgesic and antiinflammatory effects in rodents. Anesth Analg. 2003; 97(2): 402-408, indexed in Pubmed: 12873925

9. Davies N. Clinical Pharmacokinetics of Ibuprofen. Clinical Pharmacokinetics. 1998; 34(2): 101-154, doi: 10.2165/00003088-199834020 00002

10. Rousseau A, Chiap P, Ivanyi R, et al. Validation of a nonaqueous capillary electrophoretic method for the enantiomeric purity determination of R-flurbiprofen using a single-isomer amino cyclodextrin derivative. J Chromatogr A. 2008; 1204(2): 219-225, doi: 10.1016/j chroma.2008.06.006, indexed in Pubmed: 18586258.
11. Wechter WJ, Leipold DD, Quiggle DD, et al. R-Flurbiprofen (E-7869), a chemopreventive and treatment of cancer. InflammoPharmacology. 2000; 8(2): 189-206, doi: 10.1163/15685600038224.

12. Lammers I, Lhiaubet-Vallet V, Consuelo Jiménez M, et al. Stereoselective binding of flurbiprofen enantiomers and their methyl esters to human serum albumin studied by time-resolved phosphorescence. Chirality. 2012; 24(10): 840-846, doi: 10.1002/chir.22080, indexed in Pubmed: 22718496

13. Martin JE, Le Leu RK, Hu Y, et al. R-flurbiprofen suppresses distal nonmucin-producing colorectal tumors in azoxymethane-treated rats, without suppressing eicosanoid production. Am J Physiol Gastrointest Liver Physiol. 2010; 298(6): G860-G864, doi: 10.1152/ajpgi.00330.2009, indexed in Pubmed: 20338924.

14. Ciou JF, Wang PY, Wu AC, et al. Lipase-catalyzed alcoholytic resolution of $(\mathrm{R}, \mathrm{S})$-flurbiprofenyl azolides for preparation of $(R)$-NO-flurbiprofen ester prodrugs. Process Biochemistry. 2011; 46(4): 960-965, doi: 10.1016/j.procbio.2011.01.017.

15. Quann EJ, Khwaja F, Zavitz KH, et al. The aryl propionic acid R-flurbiprofen selectively induces p75NTR-dependent decreased survival of prostate tumor cells. Cancer Res. 2007; 67(7): 3254-3262, doi: 10.1158/0008-5472.CAN-06-3657, indexed in Pubmed: 17409433.

16. Wynne S, Djakiew D. NSAID inhibition of prostate cancer cell migration is mediated by Nag-1 Induction via the p38 MAPK-p75(NTR) pathway. Mol Cancer Res. 2010; 8(12): 1656-1664, doi: 10.1158/1541-7786. MCR-10-0342, indexed in Pubmed: 21097678

17. Jin $\mathrm{H}$, Wang Z, Liu L, et al. R-flurbiprofen reverses multidrug resistance, proliferation and metastasis in gastric cancer cells by p75(NTR) induction. Mol Pharm. 2010; 7(1): 156-168, doi: 10.1021/mp900189x, indexed in Pubmed: 19916560.

18. Tamborini L, Romano D, Pinto A, et al. An efficient method for the lipase-catalysed resolution and in-line purification of racemic flurbiprofen in a continuous-flow reactor. Journal of Molecular Catalysis B: Enzymatic. 2012; 84: 78-82, doi: 10.1016/j.molcatb.2012.02.008.

19. Liu JK, Patel SK, Gillespie DL, et al. R-flurbiprofen, a novel nonsteroidal anti-inflammatory drug, decreases cell proliferation and induces apoptosis in pituitary adenoma cells in vitro. J Neurooncol. 2012; 106(3): 561-569, doi: 10.1007/s11060-011-0712-4, indexed in Pubmed: 21938529.

20. Landoni MF, Lees P. Pharmacokinetics and pharmacodynamics of ketoprofen enantiomers in the horse. J Vet Pharmacol Ther. 1996; 19(6): 466-474, indexed in Pubmed: 8971676.

21. Jamali F Brocks D. Clinical Pharmacokinetics of Ketoprofen and Its Enantiomers. Clinical Pharmacokinetics. 1990; 19(3): 197-217, doi: 10.2165/00003088-199019030-00004.

22. Adachi H, loppolo F, Paoloni M, et al. Physical characteristics, pharmacological properties and clinical efficacy of the ketoprofen patch: a new patch formulation. Eur Rev Med Pharmacol Sci. 2011; 15(7): 823-830, indexed in Pubmed: 21780552.

23. Hutt AJ, Caldwell J. The importance of stereochemistry in the clinical pharmacokinetics of the 2-arylpropionic acid non-steroidal anti-inflammatory drugs. Clin Pharmacokinet. 1984; 9(4): 371-373, doi: 10.2165/00003088198409040-00007, indexed in Pubmed: 6467769.

24. Foster RT, Jamali F. High-performance liquid chromatographic assay of ketoprofen enantiomers in human plasma and urine. J Chromatogr. 1987; 416(2): 388-393, indexed in Pubmed: 3611271.

25. Rudy AC, Liu Y, Brater C, et al. Stereoselective pharmacokinetics and inversion of $(R)$ - ketoprofen in healthy volunteers. J Clin Pharmacol. 1998; 38(2 Suppl): 3S-310S, indexed in Pubmed: 9549653.

26. Kommuru TR, Khan MA, Reddy IK. Racemate and enantiomers of ketoprofen: phase diagram, thermodynamic studies, skin permeability, and use of chiral permeation enhancers. J Pharm 
Sci. 1998; 87(7): 833-840, doi: 10.1021/js9704644, indexed in Pubmed: 9649351

27. Lagrange F, Pehourcq F, Bannwarth B, et al. Passage of S- $(+)$ - and $\mathrm{R}$-(-)-ketoprofen across the human isolated perfused placenta. Fundam Clin Pharmacol. 1998; 12(3): 286-291, indexed in Pubmed: 9646061

28. Suzuki T, Kosugi Y, Hosaka M, et al. Occurrence and behavior of the chiral anti-inflammatory drug naproxen in an aquatic environment. Environ Toxicol Chem. 2014; 33(12): 2671-2678, doi: 10.1002/etc.2741, indexed in Pubmed: 25234664.

29. Camacho-Muñoz D, Petrie B, Castrignanò $E$, et al. Enantiomeric Profiling of Chiral Pharmacologically Active Compounds in the Environment with the Usage of Chiral Liquid Chromatography Coupled with Tandem Mass Spectrometry. Curr Anal Chem. 2016; 12(4):
303-314, doi: 10.2174/1573411012666151009195039, indexed in Pubmed: 27713682

30. Capone ML, Tacconelli S, Di Francesco L, et al. Pharmacodynamic of cyclooxygenase inhibitors in humans. Prostaglandins Other Lipid Mediat. 2007; 82(1-4): 85-94, doi: 10.1016/j.prostaglandins.2006.05.019, indexed in Pubmed: 17164136.

31. Zhang J, Hou Z, Yao C, et al. Purification and properties of lipase from a Bacillus strain for catalytic resolution of $(R)$-Naproxen. Journal of Molecular Catalysis B: Enzymatic. 2002; 18(4-6): 205-210, doi: 10.1016/s1381-1177(02)00097-8.

32. Jackson $M$, Labeda $D$, Becker $L$. Enantioselective hydrolysis of ethyl 2-hydroxyalkanoates by an extracellular esterase from a Bacillus sphaericus strain. Enzyme and Microbial Technology. 1995; 17(2): 175-179, doi: 10.1016/0141-0229(94)00020-r. 